\title{
Ursodeoxycholic acid attenuates 5-fluorouracil-induced mucositis in a rat model
}

\author{
SEUNG HAN KIM, HOON JAI CHUN, HYUK SOON CHOI, EUN SUN KIM, BORA KEUM, \\ YEON SEOK SEO, YOON TAE JEEN, HONG SIK LEE, SOON HO UM and CHANG DUCK KIM \\ Division of Gastroenterology and Hepatology, Department of Internal Medicine, \\ Institute of Gastrointestinal Medical Instrument Research, Korea University College of Medicine, \\ Seoul 02841, Republic of Korea
}

Received November 4, 2017; Accepted May 22, 2018

DOI: $10.3892 / 01.2018 .8893$

\begin{abstract}
Intestinal mucositis is a commonly encountered complication of chemotherapy. However, there are few effective treatments or preventive methods. Ursodeoxycholic acid (UDCA) stabilizes cell membranes, acts as an antioxidant and inhibits apoptosis, thereby exerting cytoprotective effects. The aim of the present study was to examine the ability of UDCA to protecting against chemotherapy-associated mucositis. Sprague-Dawley rats were randomly assigned to five groups: Control, vehicle + 5-fluorouracil (5-FU), 5-FU + UDCA (10 mg/kg/day), 5-FU + UDCA (100 mg/kg/day) and $5-F U+$ UDCA $(500 \mathrm{mg} / \mathrm{kg} /$ day $)$. Following randomization, a single dose of 5-FU was injected and varying amounts of UDCA was administered to each group. UDCA was administered orally to rats for 6 days, beginning 1 day prior to 5-FU administration. The rats were sacrificed 1 day following the last UDCA administration and intestinal tissue specimens were prepared for analysis. UDCA administration attenuated body weight loss, decreased inflammatory cytokine levels and curbed intestinal villus damage in the 10 and $100 \mathrm{mg} / \mathrm{kg} /$ day groups. When compared with the jejunal villi lengths in the vehicle+5-FU group $(212.8 \pm 58.0 \mu \mathrm{m})$, those in the $5-\mathrm{FU}+\mathrm{UDCA}(10 \mathrm{mg} / \mathrm{kg} / \mathrm{day})$ and $5-\mathrm{FU}+\mathrm{UDCA}$ (100 $\mathrm{mg} / \mathrm{kg} / \mathrm{day})$ groups were significantly greater [331.3 $\pm 18.0 \mu \mathrm{m}(\mathrm{P}=0.001)$ and $310.0 \pm 112.6 \mu \mathrm{m}(\mathrm{P}=0.046)$, respectively]. Tumor necrosis factor- $\alpha$ and interleukin- 6
\end{abstract}

Correspondence to: Professor Hoon Jai Chun, Division of Gastroenterology and Hepatology, Department of Internal Medicine, Institute of Gastrointestinal Medical Instrument Research, Korea University College of Medicine, 126-1 Anam-dong 5 ga, Seongbuk-gu, Seoul 02841, Republic of Korea

E-mail:drchunhj@chol.com

Abbreviations: UDCA, ursodeoxycholic acid; 5-FU, 5-fluorouracil; WBC, white blood cell; RBC, red blood cell; MPO, myeloperoxidase; IL, interleukin; TNF, tumor necrosis factor

Key words: chemotherapy-induced mucositis, chemotherapy, 5-fluorouracil, ursodeoxycholic acid, protective effect levels were reduced in the 10 and $100 \mathrm{mg} / \mathrm{kg} / \mathrm{day}$ UDCA groups $(\mathrm{P}<0.05)$. UDCA considerably attenuated the elevation in inflammatory cytokines and intestinal villus damage. The results of the study suggest that UDCA may be used as a protective agent against chemotherapy-associated intestinal mucositis.

\section{Introduction}

Intestinal mucositis is an important safety concern in patients undergoing chemotherapy. It can lead to considerable diarrhea and dehydration, which could lead to poor overall health (1-3). However, there are few effective treatments or preventive methods. Chemotherapy-induced mucositis can limit the dose of chemotherapy and increase the risk of infection or hospitalization. Consequently, mucositis during chemotherapy could increase clinical and economic burdens (4).

5-Fluorouracil (5-FU) is a frequently prescribed anticancer agent; however, it commonly causes chemotherapy-related mucositis. Approximately $80 \%$ of patients subjected to chemotherapy with 5-FU develop chemotherapy-induced mucositis (5). Inflammation, ulceration, and bleeding can occur throughout the digestive tract, particularly in the small intestine (6).

The present therapy for chemotherapy-associated mucositis mainly consists of topical analgesics, mucosal coating agents, antimicrobials, and cryotherapy (7). Recent studies have reported that chemotherapy-induced mucositis improves with keratinocyte growth factor and rhubarb extract in murine models (6-10). Current treatment methods for chemotherapy-induced mucositis usually aim to decrease the symptoms, rather than providing a complete cure. Thus, it is necessary to discover novel therapies for preventing or reducing this complication associated with chemotherapy.

Ursodeoxycholic acid (UDCA) is a physiological component present in trace amounts in human bile and has been prescribed in patients with various liver diseases (11-13). It stabilizes cell membranes, inhibits apoptosis, and acts as an antioxidant, thereby exerting cytoprotective effects (14-20). A previous study reported that UDCA protects against 
experimental ileitis by attenuating oxidative stress and intestinal barrier dysfunction (21).

We hypothesized that the direct cytoprotective effect of UDCA could protect against mucosal injury during chemotherapy. The aim of present study was to examine the ability of UDCA in protecting against chemotherapy-associated mucositis by using an animal model.

\section{Materials and methods}

Animal trial. We randomized 30 male Sprague-Dawley rats (120-130 g) to the following five groups with six rats in each group: Control (group $\mathrm{A} ; \mathrm{n}=6$ ), 5-FU (group $\mathrm{B} ; \mathrm{n}=6$ ), $5-F U$ + UDCA (10 mg/kg/day) (group C; n=6), 5-FU + UDCA (100 $\mathrm{mg} / \mathrm{kg} /$ day) (group $\mathrm{D} ; \mathrm{n}=6)$, and $5-\mathrm{FU}+\mathrm{UDCA}$ (500 mg/kg/day) (group E; $\mathrm{n}=6$ ). The rats were housed in a room maintained at a temperature of $24 \pm 2^{\circ} \mathrm{C}$, photoperiod of $12 \mathrm{~h}$, and humidity of $60 \pm 5 \%$. Water and food were provided ad libitum. On day 7 of the experiment (i.e., $24 \mathrm{~h}$ after the last dose of UDCA or its vehicle), the rats were sacrificed through $\mathrm{CO}_{2}$ asphyxiation with a flow rate of $\sim 10-30 \%$ of the chamber volume per minute, and histological and hematological analyses were performed (Fig. 1B). The Committee on the Ethics of Animal Experiments of Korea University Anam Hospital approved this protocol (permit no. KUIACUC-2015-122).

Treatment with 5-FU. Gastrointestinal mucositis was induced via the intraperitoneal administration of 5-FU. We injected a single dose of 5-FU on day 2 (400 mg/kg; JW Pharm, Seoul, Korea). Physiological saline was administered to the control group, and 5-FU solution in saline was injected intraperitoneally to rats in the four other experimental groups (Fig. 1A).

UDCA preparation. Suspensions of UDCA (Daewoong Pharmaceuticals Co., Ltd., Seoul, Korea) were prepared by adding UDCA to $10 \mathrm{ml}$ of vehicle [0.5\% carboxymethyl cellulose (JW Pharm) $+1 \%$ Tween- 80 in distilled water]. The vehicle of the same volume was also prepared and administered to rats in the control group. UDCA suspensions were administered daily by gavage for six days; the first dose was administered one day before 5-FU injection.

Diarrhea and body weight assessment. Diarrhea scores and body weights were assessed in all rats from the day of UDCA administration. The occurrence and grade of diarrhea were defined according to the diarrhea assessment (22). Diarrhea score for each rat was evaluated daily as follows: 0 , normal stool (normal); 1, considerably moist stool (mild); 2 , unformed and wet stool (moderate); and 3, watery stool (severe). The estimated mean scores were used.

Histological analysis. On day 7, we sacrificed the rats and a 2-cm specimen from the proximal lesion of all harvested small intestine was processed and placed in formalin overnight. Then, the resected intestinal specimens were dehydrated, cleared in xylol, embedded in paraffin, and microtomed into sections of constant thickness for staining. Crypt depth and villus height were evaluated using light microscopy (magnification, 100 and $\mathrm{x} 400$, respectively).
Inflammatory cytokine analysis. On day 7, the obtained intestinal tissues were cleansed and stored in RNA later at $4^{\circ} \mathrm{C}$ before use. cDNA was synthesized using the Superscript ${ }^{\mathrm{TM}}$ II real-time polymerase chain reaction System (Invitrogen, Karlsruhe, Germany) according to the manufacturer's recommendations. cDNA synthesis was performed using $500 \mathrm{ng}$ of RNA at $42^{\circ} \mathrm{C}$ and diluted 1:2 prior to use. Quantitative PCR was carried out using ABI 7900 (Applied Biosystems, Foster City, CA, USA). Primer/TaqMan probe combinations of tumor necrosis factor (TNF)- $\alpha$ (reporter sequence ACCCTCACA CTCAGATCATCTTCTC) and interleukin (IL)-6 (reporter sequence GGATATAACCAGGAAATTTGCCTAT) were designed for each target sequence. mRNA expression levels were analyzed with the comparative $\mathrm{Cq}$ method (23).

Myeloperoxidase (MPO) activity analysis. MPO activity was calculated by immunohistochemistry according to a method described previously (24). The results are represented as MPO units per high-power field.

Statistical analysis. Data are shown as mean \pm standard deviation and percentages. Statistical analyses were performed using the Kruskal-Wallis and Mann-Whitney U tests with the Bonferroni correction, as appropriate. Statistical significance was established at $\mathrm{P}<0.05$. All statistical analyses were performed using SPSS version 20.0 (IBM Corp., Armonk, NY, USA).

\section{Results}

Alteration in body weight and diarrhea score. 5-FU administration caused diarrhea and body weight loss (Fig. 2). On day 6 , mean body weight reduced to $89.6 \pm 1.7 \%$ of the original weight, and mean diarrhea score was $1.7 \pm 0.51$. Compared with the 5-FU administration group, the daily administration of UDCA attenuated body weight loss during the experiment in the 5-FU + UDCA $(10 \mathrm{mg} / \mathrm{kg} /$ day $)(\mathrm{P}=0.139)$ and the $5-\mathrm{FU}+\mathrm{UDCA}(100 \mathrm{mg} / \mathrm{kg} / \mathrm{day})$ groups $(\mathrm{P}=0.001)$. Diarrhea score also decreased in the UDCA groups.

Histological analysis: Crypt depth and villus height measurements. The evaluation of crypt depth and villus height can indicate the overall severity of mucosal injury. Histological alterations were assessed based on heights of jejunal villi. 5-FU induced considerable alterations in the mucosa (Fig. 3). Compared with the 5-FU group, the UDCA co-administration group showed a higher and an intact epithelial layer. Compared to the jejunal villi lengths in the vehicle $+5-\mathrm{FU}$ group $(212.8 \pm 58.0 \mu \mathrm{m})$, those in the 5-FU + UDCA $(100 \mathrm{mg} / \mathrm{kg} / \mathrm{day})$ and 5-FU + UDCA (10 mg/kg/day) groups were significantly greater $[310.0 \pm 112.6(\mathrm{P}=0.046)$ and $331.3 \pm 18.0 \mu \mathrm{m}(\mathrm{P}=0.001)$, respectively]. The weight-to-length ratio of the resected intestinal tissue section was also increased in UDCA co-administration groups compared with that in the 5-FU only group.

Hematological analysis. Hematological analysis revealed that white blood cell (WBC) count significantly reduced in the 5-FU group compared with the control group $(\mathrm{P}<0.05)$ (Fig. 4A). However, WBC count was also reduced in the UDCA groups. 
A

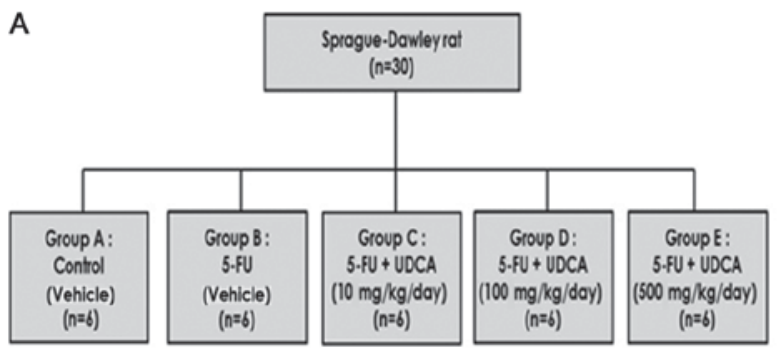

B

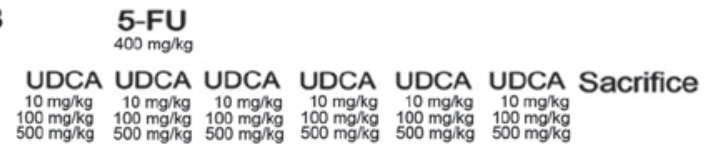

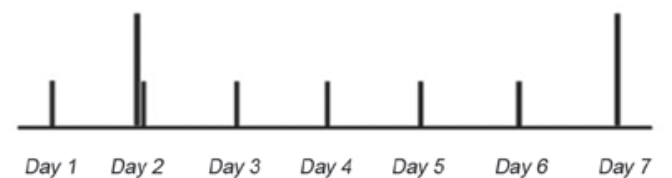

Figure 1. Study flowchart and protocol. (A) Thirty rats were used in the study, with six rats in each group. In group A, physiological saline was administered through intraperitoneal injection and $10 \mathrm{ml}$ of vehicle was administered orally. Rats in group B were orally administered $10 \mathrm{ml}$ of UDCA vehicle. 5-FU was administered on experimental day 2 to rats in groups B-E. In combination with 5-FU administration, rats in groups C-E were administered UDCA on experimental days 1-6 via oral gavage at the indicated doses. (B) UDCA suspension was administered daily by gavage. UDCA, ursodeoxycholic acid; 5-FU, 5-fluorouracil.
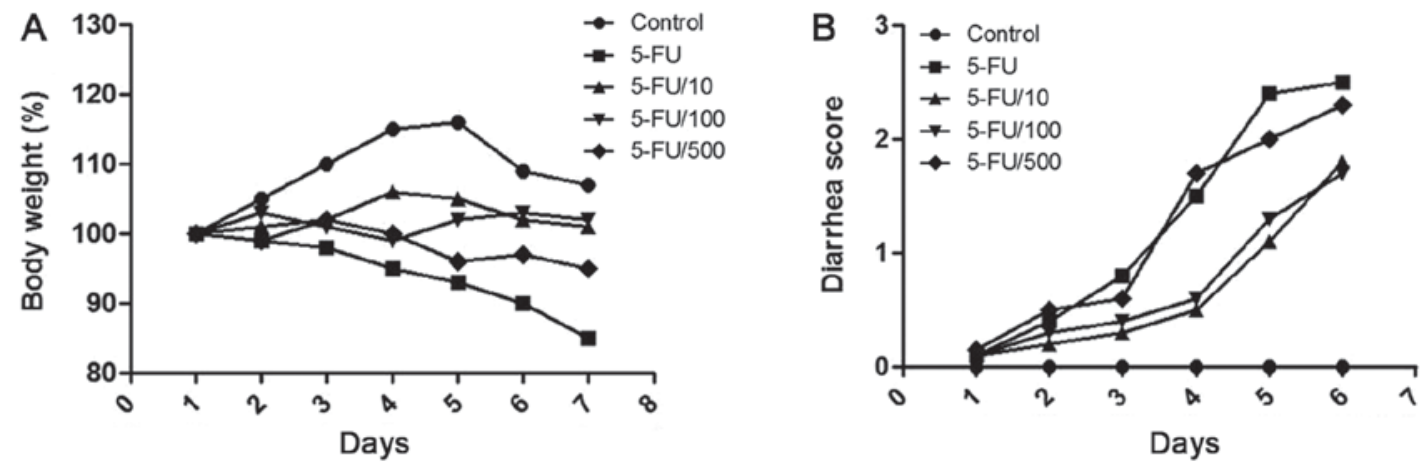

Figure 2. Assessment of diarrhea score and body weight. All rats were checked daily for (A) body weight loss and (B) severity of diarrhea. 5-FU, 5-fluorouracil.

red blood cell (RBC) count and hemoglobin level were not different among the groups (Fig. 4B, C).

Inflammatory cytokine analysis. The mRNA expression of IL- 6 and TNF- $\alpha$ was increased by approximately two-fold because of 5-FU (Fig. 4D and E). UDCA administration $(100 \mathrm{mg} / \mathrm{kg} /$ day $)$ significantly reduced the 5-FU-mediated mRNA expression of both TNF- $\alpha$ and IL-6 (P<0.05).

MPO activity. The activity of MPO (number of MPO-positive cells per high-power field) was compared among the groups (Fig. 4F). MPO activity significantly decreased in the 100 and $10 \mathrm{mg} / \mathrm{kg}$ /day UDCA groups compared with corresponding levels in the 5-FU group $(\mathrm{P}<0.05)$.

\section{Discussion}

The aim of this study was to evaluate the protective effect of UDCA against chemotherapy-associated intestinal mucositis. Our results showed that UDCA attenuates chemotherapy-induced reduction in villus height and decreases levels of inflammatory cytokines and MPO activity.

$5-\mathrm{FU}$ is frequently used for treating gastrointestinal malignancy. However, approximately $80 \%$ of patients subjected to chemotherapy with 5-FU develop chemotherapy-induced mucositis (5). This adverse effect can worsen the quality of life in patients undergoing chemotherapy and can cause an early cessation of chemotherapy. Therefore, effective preventive and therapeutic agents against chemotherapy-induced intestinal mucositis are needed.
UDCA has demonstrated efficacy in numerous types of hepatic disorders, without considerable adverse effects upon long-term administration (25-27). The exact mechanism of UDCA in improving hepatic dysfunction remains to be established; however, some assumptions have been made. In these hypotheses, UDCA has been suggested to protect the liver from the toxic effect of hydrophobic bile acids by altering the organization of the bile acid pool (28-30). Further, UDCA exerts a direct cytoprotective action by acting as an antioxidant, inhibiting apoptosis, and stabilizing membranes (14-17). UDCA decreased oxidative stress and intestinal permeability in an indomethacin-induced ileitis model, relieved ibuprofen-induced enteropathy, and improved trinitrobenzene sulfonic acid sodium salt-induced colitis $(21,31,32)$. These effects coupled with its long-term safety have valuable implications and highlight the potential of UDCA as a therapeutic agent in non-hepatic disorders $(26,27,33)$.

Consistent with previous findings, 5-FU administration in this study led to considerable small bowel mucositis. The induced mucositis was characterized by villus height reduction and damage to crypts in the small intestine. The co-administration of UDCA attenuated the degree of 5-FU-induced mucosal injury and associated clinical symptoms, such as body weight reduction and diarrhea. Therefore, UDCA co-administration may be effective in treating 5-FU-associated intestinal mucositis and its associated manifestations.

Regarding the pathogenesis of chemotherapy-associated intestinal mucositis, several pathogenic components have been suggested to present direct cytotoxicity, and stimulate abnormal inflammation and hypoproliferation (2,34,35). 5-FU-induced apoptosis could be provoked by the initiation of the extrinsic 

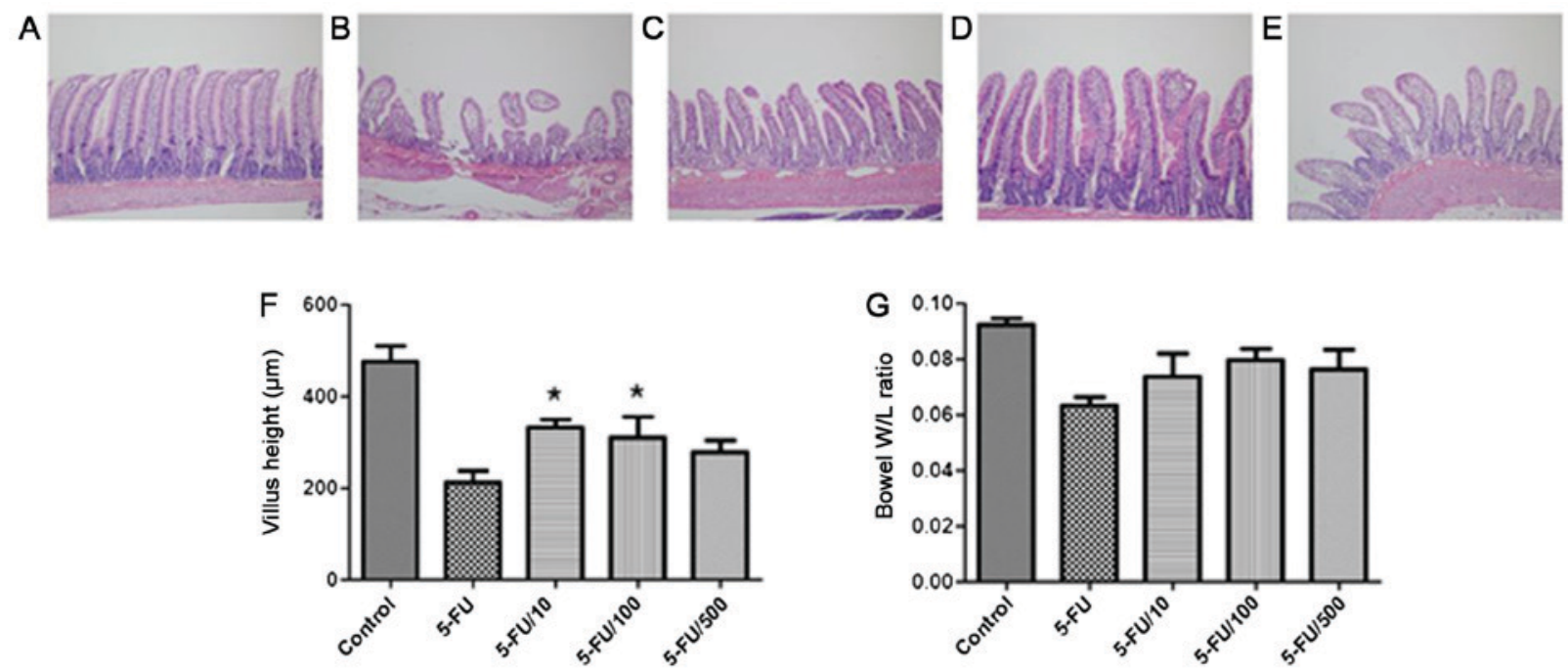

Figure 3. Histological features of the resected intestine and villus height and weight-to-length ratio of the resected specimen according to groups. Hematoxylin and eosin staining was performed in samples from the (A) Control, (B) 5-FU, (C) 5 -FU + UDCA (10 mg/kg/day), (D) 5 -FU + UDCA (100 mg/kg/day) and (E) $5-\mathrm{FU}+\mathrm{UDCA}(500 \mathrm{mg} / \mathrm{kg} /$ day) groups. Histological examination of the jejunal villi and crypts are presented (magnification, $\mathrm{x} 100)$. (F) Villus height and $(\mathrm{G}) \mathrm{W} / \mathrm{L}$ ratio of the resected jejunal specimen were measured. Data are shown as the mean \pm standard deviation. ${ }^{*} \mathrm{P}<0.05$ vs. the 5 -FU group. W/L, weight-to-length; 5-FU, 5-fluorouracil; UDCA, ursodeoxycholic acid.
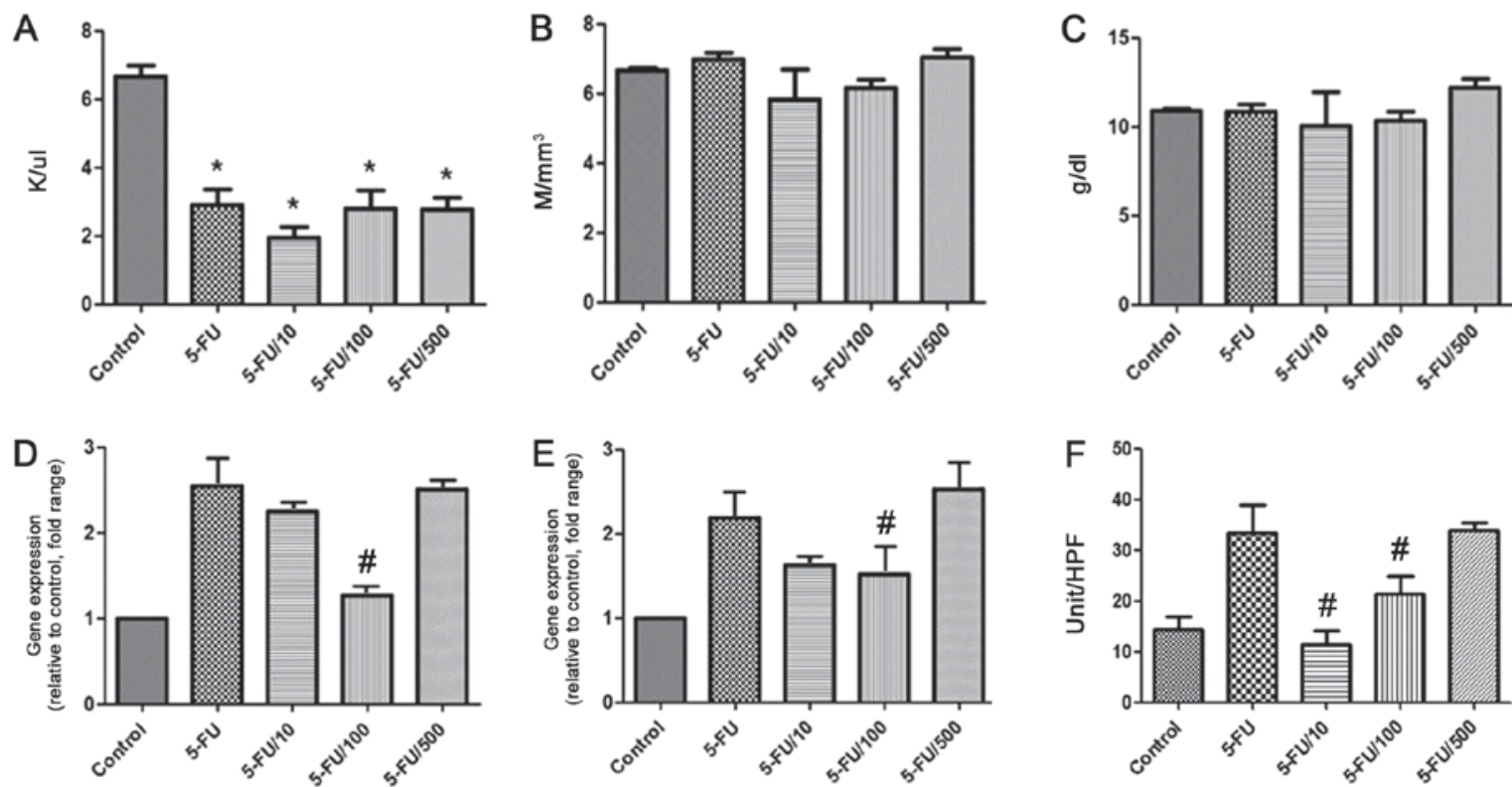

Figure 4. Effect of ursodeoxycholic acid on hematology, levels of inflammatory cytokines, and MPO levels in different groups. (A) White blood cell count, (B) red blood cell count and (C) hemoglobin level. Data are presented as the mean \pm standard deviation. Secreted (D) interleukin-6 and (E) tumor necrosis factor- $\alpha$ mRNA levels. Data are represented as fold-changes relative to the control. (F) MPO activity. Data are shown as the mean \pm standard deviation. ${ }^{*} \mathrm{P}<0.05$ vs. the control; ${ }^{\mathrm{P}} \mathrm{P}<0.05$ vs. the 5 -FU group. 5 -FU, 5 -fluorouracil.

apoptotic pathway, which is mediated by inflammatory cytokines (36). Previous studies have shown that apoptosis caused by 5 -FU administration is substantially ameliorated through the inhibition of cytokines (37-39). In the current study, UDCA co-administration $(100 \mathrm{mg} / \mathrm{kg} /$ day $)$ reduced levels of TNF- $\alpha$ and IL- 6 in the small intestine. This indicated that UDCA may protect against chemotherapy-associated mucositis by decreasing the levels of inflammatory cytokines.

The dose of UDCA was decided based on a previous report that UDCA at a dose of $10 \mathrm{mg} / \mathrm{kg} /$ day relieves intestinal inflammation (40); however, the opposite effect occurs at a dose of approximately $400 \mathrm{mg} / \mathrm{kg} / \mathrm{day}$ (41). An investigation with colitis models indicated that UDCA at doses of $10-50 \mathrm{mg} / \mathrm{kg} /$ day ameliorates enteropathy, whereas UDCA at a dose of $400 \mathrm{mg} / \mathrm{kg} / \mathrm{day}$ induces cell membrane damage and solubilization due to an increase in hydrophobic bile acid, resulting from an increase in secondary bile acid levels. In the current study, UDCA at doses of 100 and $10 \mathrm{mg} / \mathrm{kg} / \mathrm{day}$ exerted a protective effect against chemotherapy-induced mucositis, as indicated by an improvement in reduced villus height. The optimal dose should be established for chemotherapy-associated mucositis. 
The present study has limitations, including the lack of assessment of other roles of UDCA in the prevention of chemotherapy-associated mucositis. Furthermore, effects on the intestine of UDCA alone at different doses were not evaluated.

However, to accurately evaluate the action of UDCA in chemotherapy-induced mucositis, pro-inflammatory cytokine production and damage to mucosal components were assessed. The current findings demonstrated the protective effect of UDCA against chemotherapy-associated mucositis. Further studies are necessary to investigate other roles of UDCA against chemotherapy-associated mucositis and to confirm the ideal dose.

UDCA is currently prescribed for the treatment of various hepatic diseases without significant adverse events. Owing to its cytoprotective effect, it can be assumed that UDCA can be easily applied to treat chemotherapy-induced mucositis. However, its possible adverse effects, such as skin rash, nephritis, and vasculitis, also should be considered (42).

In conclusion, UDCA considerably decreased inflammatory cytokine levels, intestinal villus damage, and MPO activity. These results highlight the possibility of UDCA, at a suitable dose, as a protective agent against chemotherapy-associated intestinal mucositis.

\section{Acknowledgements}

Not applicable.

\section{Funding}

The present study was supported by the Ministry of Trade, Industry \& Energy (Korea) under the Industrial Technology Innovation 'Development of diagnostic device for functional dyspepsia based on Korean-Western medicine fusion abdominal diagnosis' (grant no. 10060251), and by Daewoong Pharmaceuticals Co. Ltd. (Seoul, Korea).

\section{Availability of data and materials}

All data generated or analyzed during this study are included in this published article.

\section{Authors' contributions}

SHK, BK and HJC designed the research, and SHK and BK performed the experiments. ESK, YTJ, HSL and CDK assisted in data acquisition, and creating the tables and figures. HSC, YSS and SHU analyzed the data. SHK wrote the manuscript.

\section{Ethics approval and consent to participate}

The study was approved by the Ethics Committee of Animal Experiments at Korea University Anam Hospital (approval no. KUIACUC-2015-122).

\section{Consent for publication}

Not applicable.

\section{Competing interests}

Daewoong Pharmaceuticals Co., Ltd. (Seoul, Korea) provided the UDCA used in the experiments and also financially supported the present study.

\section{References}

1. Benson AB III, Ajani JA, Catalano RB, Engelking C, Kornblau SM, Martenson JA Jr, McCallum R, Mitchell EP, O'Dorisio TM, Vokes EE and Wadler S: Recommended guidelines for the treatment of cancer treatment-induced diarrhea. J Clin Oncol 22: 2918-2926, 2004.

2. Bowen JM, Gibson RJ, Cummins AG and Keefe DM: Intestinal mucositis: The role of the Bcl-2 family, p53 and caspases in chemotherapy-induced damage. Support Care Cancer 14: 713-731, 2006.

3. Keefe DMK, Brealey J, Goland GJ and Cummins AG: Chemotherapy for cancer causes apoptosis that precedes hypoplasia in crypts of the small intestine in humans. Gut 47: 632-637, 2000.

4. Maioli TU, de Melo Silva B, Dias MN, Paiva NC, Cardoso VN, Fernandes SO, Carneiro CM, Dos Santos Martins F and de Vasconcelos Generoso S: Pretreatment with Saccharomyces boulardii does not prevent the experimental mucositis in Swiss mice. J Negat Results Biomed 13: 6, 2014.

5. Smith CL, Geier MS, Yazbeck R, Torres DM, Butler RN and Howarth GS: Lactobacillus fermentum BR11 and fructo-oligosaccharide partially reduce jejunal inflammation in a model of intestinal mucositis in rats. Nutr Cancer 60: 757-767, 2008.

6. Sonis ST, Elting LS, Keefe D, Peterson DE, Schubert M, Hauer-Jensen M, Bekele BN, Raber-Durlacher J, Donnelly JP, Rubenstein EB, et al: Perspectives on cancer therapy-induced mucosal injury: Pathogenesis, measurement, epidemiology, and consequences for patients. Cancer 100 (9 Suppl): S1995-S2025, 2004.

7. Gibson RJ, Keefe DM, Lalla RV, Bateman E, Blijlevens N, Fijlstra M, King EE, Stringer AM, van der Velden WJ, Yazbeck R, et al: Systematic review of agents for the management of gastrointestinal mucositis in cancer patients. Support Care Cancer 21: 313-326, 2013.

8. Rubenstein EB, Peterson DE, Schubert M, Keefe D, McGuire D, Epstein J, Elting LS, Fox PC, Cooksley C, Sonis ST, et al: Clinical practice guidelines for the prevention and treatment of cancer therapy-induced oral and gastrointestinal mucositis. Cancer 100 (9 Suppl): S2026-S2046, 2004.

9. Bhatt V, Vendrell N, Nau K, Crumb D and Roy V: Implementation of a standardized protocol for prevention and management of oral mucositis in patients undergoing hematopoietic cell transplantation. J Oncol Pharm Pract 16: 195-204, 2010.

10. Bajic JE, Eden GL, Lampton LS, Cheah KY, Lymn KA, Pei JV, Yool AJ and Howarth GS: Rhubarb extract partially improves mucosal integrity in chemotherapy-induced intestinal mucositis. World J Gastroenterol 22: 8322-8333, 2016.

11. Hwang MJ and Kim TN: Diffuse-type Caroli disease with characteristic central dot sign complicated by multiple intrahepatic and common bile duct stones. Clin Endosc 50: 400-403, 2017.

12. Kwon CI and Lehman GA: Mechanisms of biliary plastic stent occlusion and efforts at prevention. Clin Endosc 49: 139-146, 2016.

13. Yoo KH, Kwon CI, Yoon SW, Kim WH, Lee JM, Ko KH, Hong SP and Park PW: An impacted pancreatic stone in the papilla induced acute obstructive cholangitis in a patient with chronic pancreatitis. Clin Endosc 45: 99-102, 2012.

14. Güldütuna S, Zimmer G, Imhof M, Bhatti S, You T and Leuschner U: Molecular aspects of membrane stabilization by ursodeoxycholate [see comment]. Gastroenterology 104: 1736-1744, 1993.

15. Rodrigues CM, Fan G, Ma X, Kren BT and Steer CJ: A novel role for ursodeoxycholic acid in inhibiting apoptosis by modulating mitochondrial membrane perturbation. J Clin Invest 101: 2790-2799, 1998 .

16. Rodrigues CM, Fan G, Wong PY, Kren BT and Steer CJ: Ursodeoxycholic acid may inhibit deoxycholic acid-induced apoptosis by modulating mitochondrial transmembrane potential and reactive oxygen species production. Mol Med 4: 165-178, 1998. 
17. Lapenna D, Ciofani G, Festi D, Neri M, Pierdomenico SD Giamberardino MA and Cuccurullo F: Antioxidant properties of ursodeoxycholic acid. Biochem Pharmacol 64: 1661-1667, 2002.

18. Cao A, Wang L, Chen X, Guo H, Chu S, Zhang X and Peng W: Ursodeoxycholic acid ameliorated diabetic nephropathy by attenuating hyperglycemia-mediated oxidative stress. Biol Pharm Bull 39: 1300-1308, 2016.

19. Mroz MS, Lajczak NK, Goggins BJ, Keely S and Keely SJ: The bile acids, deoxycholic acid and ursodeoxycholic acid, regulate colonic epithelial wound healing. Am J Physiol Gastrointest Liver Physiol 314: G378-G387, 2018.

20. Lajczak NK, Saint-Criq V, O'Dwyer AM, Perino A, Adorini L, Schoonjans K and Keely SJ: Bile acids deoxycholic acid and ursodeoxycholic acid differentially regulate human $\beta$-defensinand -2 secretion by colonic epithelial cells. FASEB J 31 : 3848-3857, 2017.

21. Bernardes-Silva CF, Damião AO, Sipahi AM, Laurindo FR, Iriya K, Lopasso FP, Buchpiguel CA, Lordello ML, Agostinho CL and Laudanna AA: Ursodeoxycholic acid ameliorates experimental ileitis counteracting intestinal barrier dysfunction and oxidative stress. Dig Dis Sci 49: 1569-1574, 2004.

22. Kurita A, Kado S, Kaneda N, Onoue M, Hashimoto S and Yokokura T: Modified irinotecan hydrochloride (CPT-11) administration schedule improves induction of delayed-onset diarrhea in rats. Cancer Chemother Pharmacol 46: 211-220, 2000.

23. Livak KJ and Schmittgen TD: Analysis of relative gene expression data using real-time quantitative PCR and the 2(-Delta Delta C(T)) method. Methods 25: 402-408, 2001

24. Krawisz JE, Sharon P and Stenson WF: Quantitative assay for acute intestinal inflammation based on myeloperoxidase activity. Assessment of inflammation in rat and hamster models. Gastroenterology 87: 1344-1350, 1984.

25. Lindor KD, Kowdley KV, Luketic VA, Harrison ME, McCashland T, Befeler AS, Harnois D, Jorgensen R, Petz J, Keach J, et al: High-dose ursodeoxycholic acid for the treatment of primary sclerosing cholangitis. Hepatology 50: 808-814, 2009.

26. Cullen SN, Rust C, Fleming K, Edwards C, Beuers U and Chapman RW: High dose ursodeoxycholic acid for the treatment of primary sclerosing cholangitis is safe and effective. J Hepatol 48: 792-800, 2008.

27. Oh B, Choi WS, Park SB, Cho B, Yang YJ, Lee ES and Lee JH: Efficacy and safety of ursodeoxycholic acid composite on fatigued patients with elevated liver function and/or fatty liver: A multi-centre, randomised, double-blinded, placebo-controlled trial. Int J Clin Pract 70: 302-311, 2016.

28. Renner EL, Lake JR, Cragoe EJ Jr, Van Dyke RW and Scharschmidt BF: Ursodeoxycholic acid choleresis: Relationship to biliary HCO-3 and effects of $\mathrm{Na}+\mathrm{H}+$ exchange inhibitors. Am J Physiol 254: G232-G241, 1988.

29. Sagawa H, Tazuma S and Kajiyama G: Protection against hydrophobic bile salt-induced cell membrane damage by liposomes and hydrophilic bile salts. Am J Physiol 264: G835-G839, 1993.

30. Hofmann AF: Pharmacology of ursodeoxycholic acid, an enterohepatic drug. Scand J Gastroenterol Suppl 204: 1-15, 1994.

31. Kullmann F, Arndt H, Gross V, Rüschoff J and Schölmerich J: Beneficial effect of ursodeoxycholic acid on mucosal damage in trinitrobenzene sulphonic acid-induced colitis. Eur J Gastroenterol Hepatol 9: 1205-1211, 1997.
32. Lloyd-Still JD, Beno DW, Uhing MR, Jiyamapa-Serna VA and Kimura RE: Ursodeoxycholic acid ameliorates ibuprofen-induced enteropathy in the rat. J Pediatr Gastroenterol Nutr 32: 270-273, 2001.

33. Braga MF, Grace MG, Lenis J, Kennedy FP, Teplinsky AL, Roederer G, Palumbo PJ, Colin P and Leiter LA: Efficacy and safety of ursodeoxycholic acid in primary, type IIa or IIb hypercholesterolemia: A multicenter, randomized, double-blind clinical trial. Atherosclerosis 203: 479-482, 2009.

34. Duncan M and Grant G: Oral and intestinal mucositis - causes and possible treatments. Aliment Pharmacol Ther 18: 853-874, 2003.

35. Daniele B, Secondulfo M, De Vivo R, Pignata S, De Magistris L, Delrio P, Palaia R, Barletta E, Tambaro R and Carratù R: Effect of chemotherapy with 5-fluorouracil on intestinal permeability and absorption in patients with advanced colorectal cancer. J Clin Gastroenterol 32: 228-230, 2001.

36. Kato S, Hayashi S, Kitahara Y, Nagasawa K, Aono $\mathrm{H}$, Shibata J, Utsumi D, Amagase K and Kadowaki M: Saireito (TJ-114), a Japanese traditional herbal medicine, reduces 5-fluorouracil-induced intestinal mucositis in mice by inhibiting cytokine-mediated apoptosis in intestinal crypt cells. PLoS One 10: e0116213, 2015

37. Wu ZQ, Han XD, Wang Y, Yuan KL, Jin ZM, Di JZ, Yan J, Pan Y, Zhang P, Huang XY, et al: Interleukin-1 receptor antagonist reduced apoptosis and attenuated intestinal mucositis in a 5 -fluorouracil chemotherapy model in mice. Cancer Chemother Pharmacol 68: 87-96, 2011.

38. Yasuda M, Kato S, Yamanaka N, Iimori M, Matsumoto K, Utsumi D, Kitahara Y, Amagase K, Horie S and Takeuchi K: 5-HT(3) receptor antagonists ameliorate 5-fluorouracil-induced intestinal mucositis by suppression of apoptosis in murine intestinal crypt cells. Br J Pharmacol 168: 1388-1400, 2013.

39. Huang TY, Chu HC, Lin YL, Ho WH, Hou HS, Chao YC and Liao CL: Minocycline attenuates 5-fluorouracil-induced small intestinal mucositis in mouse model. Biochem Biophys Res Commun 389: 634-639, 2009.

40. Kullmann F, Gross V, Rüschoff J, Arndt H, Benda W, Winkler von Mohrenfels A and Schölmerich J: Effect of ursodeoxycholic acid on the inflammatory activity of indomethacin-induced intestinal inflammation in rats. Z Gastroenterol 35: 171-178, 1997.

41. Uchida A, Yamada T, Hayakawa $\mathrm{T}$ and Hoshino $\mathrm{M}$ : Taurochenodeoxycholic acid ameliorates and ursodeoxycholic acid exacerbates small intestinal inflammation. Am J Physiol 272: G1249-G1257, 1997.

42. Kotb MA: Molecular mechanisms of ursodeoxycholic acid toxicity \& side effects: Ursodeoxycholic acid freezes regeneration \& induces hibernation mode. Int J Mol Sci 13: 8882-8914, 2012. 